\title{
Randomised trial comparing propranolol with atenolol in immediate treatment of suspected myocardial infarction
}

\author{
R G WILCOX, J M ROLAND, D C BANKS, J R HAMPTON, J R A MITCHELL
}

\section{Summary and conclusions}

The value of beta-blockade for suspected acute myocardial infarction was assessed by determining the sixweek and one-year mortality rates in patients started on propranolol, atenolol, or placebo immediately on entry to a coronary care unit. A total of 388 patients entered this double-blind, randomised study, and when analysed on the basis of the initial, intention-to-treat categories there was no significant difference between the three groups in respect of the mortality rate at one year. There was, however, a high withdrawal rate from the trial; the reasons for this illustrate problems of physician compliance and interpretation of data, which are common to all early-entry trials of haemodynamically active agents in acute myocardial infarction.

\section{Introduction}

Despite many clinical trials the role of beta-blockade in the immediate treatment of patients with acute myocardial infarction is still not clear. ${ }^{1-5}$ In some of the trials that used propranolol the dosage may have been insufficient to achieve beta-blockade. ${ }^{\circ}$ Moreover, since these earlier trials increasingly cardioselective beta-blockers have been developed.

We have therefore investigated the effect of giving higher doses of a non-selective beta-blocker (propranolol) or of giving a selective beta-blocker (atenolol) to patients with suspected myocardial infarction within the past 24 hours were considered for we describe the effect of these regimens on outcome as judged by mortality at six weeks and one year.

\footnotetext{
Department of Medicine, University Hospital, Nottingham NG7 2UH

R G WILCOX, BSC, MRCP, lecturer

J R HAMPTON, DM, FRCP, reader

J R A MITCHELL, DM, FRCP, professor

Department of Therapeutics, City Hospital, Nottingham NG5 1PB J M ROLAND, MRCP, research fellow

D C BANKS, MD, FRCP, senior lecturer
}

\section{Patients and methods}

All patients admitted to the coronary care units of the City and General Hospitals, Nottingham, with a clinical diagnosis of suspected myocardial infarction within the past 24 hours were considered for entry to the trial. There was no age limit, and admission to the coronary care units depended solely on availability of beds.

The patients were examined on admission by the duty medical officer, who excluded from the trial anyone who: $(a)$ was already taking a beta-blocker; $(b)$ had severe heart failure (as defined by breathlessness, elevated jugular venous pressure, and basal crepitations); (c) had sinus bradycardia of under 40 beats/minute; $(d)$ was in secondor third-degree heart block; $(e)$ had a systolic blood pressure of under $90 \mathrm{~mm} \mathrm{Hg} ;(f)$ had a history of asthma or diabetes mellitus; or $(g)$ was not a resident of Nottingham or was already in another study. All the excluded patients were followed up to determine their outcome at six weeks and one year after entry to the unit.

The patients who entered the trial were allocated to one of three drug regimens according to a predetermined randomised code for each hospital and received three tablets daily from the appropriately numbered pack. All the tablets were identical so the trial was doubleblind, and the first tablets were given immediately after initial assessment. The three regimens were: propranolol $40 \mathrm{mg}$ three times daily, atenolol $50 \mathrm{mg}$ twice daily plus midday placebo, and placebo three times daily. The following information was recorded in the coronary care unit: initial then daily electrocardiogram; cardiac enzyme activities (serum hydroxybutyrate dehydrogenase and aspartate transaminase at General Hospital, and creatine phosphokinase and lactate dehydrogenase at City Hospital); two-hourly pulse rate and blood pressure; and diamorphine, diuretic, and digoxin requirements. Additionally, a group of patients was randomly selected for 24-hour electrocardiogram tape recordings with Oxford cassette recorders. ${ }^{7}$ After 24-72 hours the patients were transferred to general medical wards until their discharge. Throughout their stay in hospital the patients remained under the care of their admitting doctor.

The regimens were continued after discharge until the patients were seen by the trial team in a special clinic about six weeks after admission to the coronary care unit. At this stage those patients who had been admitted with chest pain but in whom there was no past or present evidence of ischaemic heart disease were removed from the trial but continued attending the follow-up clinic. The others continued taking tablets but only twice daily (propranolol $80 \mathrm{mg}$, atenolol $50 \mathrm{mg}$, and placebo). All patients were seen every three months until one year after their admission.

At each visit the patients were asked about their level of activity and employment, symptoms of breathlessness, chest pain, other drug 
treatment, and side effects. The data on side effects were separately recorded as either volunteered or elicited. Resting pulse rates and blood pressures were noted, and an electrocardiogram was recorded if any abnormality of cardiac rhythm was detected clinically. Compliance with treatment was assessed by tablet counts at each visit.

Patients could be withdrawn at any stage for the following reasons : heart failure, heart block, bradycardia, hypotension (as defined above), the development of dysrhythmias that in the opinion of the admitting doctor required treatment with beta-blockers, angina not satisfactorily controlled with glyceryl trinitrate, or if the diagnosis of myocardial infarction was disproved by another diagnosis.

The cause of death was established from hospital and general practitioners' records and from postmortem reports.

\section{DIAGNOSTIC CATEGORIES}

The patients were categorised according to electrocardiographic and enzyme changes as follows: (a) definite myocardial infarctiona convincing history accompanied by pathological $Q$ waves in the electrocardiogram and peak cardiac enzyme activities over twice the normal value; $(b)$ probable infarction-a convincing history with either pathological $Q$ waves or a rise in cardiac enzyme activities to over twice the normal value; $(c)$ possible infarction-a convincing history accompanied by electrocardiographic abnormalities that were not diagnostic of myocardial infarction and by an increase in cardiac enzyme activities that did not exceed twice the upper limit of normal ; $(d)$ ischaemic heart disease-a history of myocardial infarction or angina but without sequential electrocardiographic or enzyme changes during the present admission; (e) chest pain of unknown cause-no history of myocardial infarction or angina and no sequential electrocardiographic or enzyme changes; $(f)$ other proved diagnosis to explain the chest pain.

Statistics-Significance of differences between groups was determined by performing $\chi^{2}$ analysis.

\section{Results}

In 12 months 662 patients were considered for entry to the study and 388 of these were randomly allocated to the trial regimens. The reasons for exclusion were: already taking beta-blockers ( 97 patients); hypotension, heart failure, heart block, or sinus bradycardia (64); diabetes (25); asthma (22); and already in other studies or only visiting Nottingham (66).

Of the 388 patients admitted to the trial, 132 received propranolol, 127 atenolol, and 129 placebo. Table I shows that the three groups were well matched for several characteristics. They were also well matched on entry for blood pressure, mild or moderate heart failure, heart rate, dysrhythmias, other electrocardiographic abnormalities, and distribution of initial levels of cardiac enzymes. Our wish to perform an early-entry study resulted in about one-third of the patients in each group receiving their first trial tablet within four hours of the onset of symptoms, two-thirds within eight hours, and most of the remainder within 12 hours (table II).

Table III shows that the distribution of diagnoses within the three treatment groups was also comparable. Two-thirds of the patients in each group were transferred from the coronary care unit to a general ward within 48 hours, and $85 \%$ of each group left hospital within 10 days. There were no differences between the groups in the need for analgesics, digoxin, diuretics, or antidysrhythmic treatment, either during the hospital stay or during follow-up. The distribution of anterior, inferior, and unsited infarctions was also similar between the three groups.
TABLE II-Number of patients receiving first tablet of trial at given time after onset of symptoms

\begin{tabular}{|c|c|c|c|c|c|c|c|c|}
\hline & \multirow{2}{*}{ Drug } & & & \multicolumn{5}{|c|}{ Time from onset (hr) } \\
\hline & & & & $<2$ & -4 & -6 & -8 & -24 \\
\hline $\begin{array}{l}\text { Propranolol. . } \\
\text { Atenolol } \\
\text { Placebo }\end{array}$ & $\begin{array}{l}\cdots \\
\cdots\end{array}$ & $\begin{array}{l}\ldots \\
\cdots\end{array}$ & $\begin{array}{l}\cdots \\
\cdots\end{array}$ & $\begin{array}{l}9 \\
2 \\
6\end{array}$ & $\begin{array}{l}36 \\
36 \\
32\end{array}$ & $\begin{array}{l}33 \\
45 \\
33\end{array}$ & $\begin{array}{l}18 \\
10 \\
17\end{array}$ & $\begin{array}{l}36 \\
34 \\
41\end{array}$ \\
\hline
\end{tabular}

TABLE III-Diagnoses at time of death or discharge

\begin{tabular}{|c|c|c|c|c|c|c|c|}
\hline & \multirow{2}{*}{\multicolumn{4}{|c|}{ Diagnosis }} & \multicolumn{3}{|c|}{ Drug } \\
\hline & & & & & \multirow{2}{*}{$\begin{array}{c}\text { Propranolol } \\
72 \\
10 \\
13\end{array}$} & \multirow{2}{*}{$\begin{array}{c}\text { Atenolol } \\
\\
60 \\
13 \\
15\end{array}$} & \multirow{2}{*}{$\begin{array}{c}\text { Placebo } \\
\\
59 \\
17 \\
10\end{array}$} \\
\hline $\begin{array}{c}\text { Infarction: } \\
\text { Definite } \\
\text { Probable } \\
\text { Possible }\end{array}$ & $\begin{array}{l}. \\
\therefore \\
\end{array}$ & $\begin{array}{l}. \\
\cdots \\
\end{array}$ & $\begin{array}{l}. \\
\cdots \\
\end{array}$ & $\begin{array}{l}\cdots \\
\cdots\end{array}$ & & & \\
\hline Total No ( & o).. & . & .. & . & $95(72)$ & $88(69)$ & $86(67)$ \\
\hline $\begin{array}{l}\text { Site of infarcti } \\
\text { Anterior } \\
\text { Inferior } \\
\text { Unsited } \\
\text { Ischaemic hear } \\
\text { Chest pain of } \\
\text { Other . . }\end{array}$ & $\begin{array}{c}\text { on: } \\
\ldots \\
\ldots \\
\ddot{\text { dis }} \\
\text { unkn } \\
\ldots\end{array}$ & $\begin{array}{c}. . \\
. \\
\text { se } \\
\text { n cause } \\
\ldots\end{array}$ & $\begin{array}{l}\cdots \\
\cdots \\
\cdots \\
\cdots\end{array}$ & $\begin{array}{l}\because \\
\because \\
\because \\
\cdots\end{array}$ & $\begin{array}{r}62 \\
30 \\
3 \\
13 \\
19 \\
5\end{array}$ & $\begin{array}{r}50 \\
32 \\
6 \\
15 \\
21 \\
3\end{array}$ & $\begin{array}{r}50 \\
33 \\
3 \\
12 \\
26 \\
5\end{array}$ \\
\hline
\end{tabular}

\section{WITHDRAWALS}

In the first six weeks after entry to the study $31 \%$ of the patients given placebo, $33 \%$ of those given propranolol, and $40 \%$ of those given atenolol were withdrawn from treatment (table IV). Most of the withdrawals occurred in the first 72 hours of treatment in all three groups, and a similar proportion of patients withdrawn from each group had anterior or inferior infarction. Whereas hypotension and bradycardia (as defined above) accounted for a large number of withdrawals in the two groups given beta-blockers, more patients were withdrawn from the placebo group for "other" reasons. These were mainly non-specific such as headache, tiredness, and rash, though a disproportionate number of patients with "chest pain of unknown cause" were withdrawn at this stage. There were no excess withdrawals in any of the groups because of continuing chest pain, tachycardia, or hypertension.

In addition to the patients electively withdrawn before or at six weeks according to the trial protocol-that is, where another diagnosis had been made or infarction had not been confirmed in the absence of a past history of angina or infarction -17 patients allocated to proprano-

TABLE IV-Reasons for withdrawal from trial in first six weeks

\begin{tabular}{|c|c|c|c|c|c|c|c|}
\hline & \multirow{2}{*}{\multicolumn{2}{|c|}{ Reason }} & & & \multicolumn{3}{|c|}{ Drug } \\
\hline & & & & & Propranolol & Atenolol & Placebo \\
\hline \multirow{6}{*}{$\begin{array}{l}\text { Hypotension } \\
\text { Bradycardia } \\
\text { Heart block: } \\
\text { 2nd degree } \\
\text { 3rd degree } \\
\text { Heart failure } \\
\text { Asthma .. } \\
\text { Other* .. }\end{array}$} & $\because$ & $\because$ & $\because$ & $\because$ & $\begin{array}{r}14 \\
8\end{array}$ & $\begin{array}{r}18 \\
9\end{array}$ & $\begin{array}{l}2 \\
3\end{array}$ \\
\hline & & & & & & & \\
\hline & $\cdots$ & $\cdots$ & $\cdots$ & $\because$ & 3 & $\begin{array}{l}1 \\
4\end{array}$ & 2 \\
\hline & $\because$. & $\cdots$ & $\because$. & $\begin{array}{l}\cdots \\
\cdots\end{array}$ & $\frac{1}{7}$ & 3 & 8 \\
\hline & .. & .. & . & .. & 1 & 0 & $\begin{array}{r}0 \\
02\end{array}$ \\
\hline & . & . & $\cdots$ & $\cdots$ & 10 & 16 & 23 \\
\hline \multicolumn{3}{|c|}{ Total No $(\%)$} & & & $44(33)$ & $51(40)$ & $40(31)$ \\
\hline
\end{tabular}

*Other diagnoses or non-compliance with protocol.

TABLE I-Characteristics of 388 patients admitted to trial

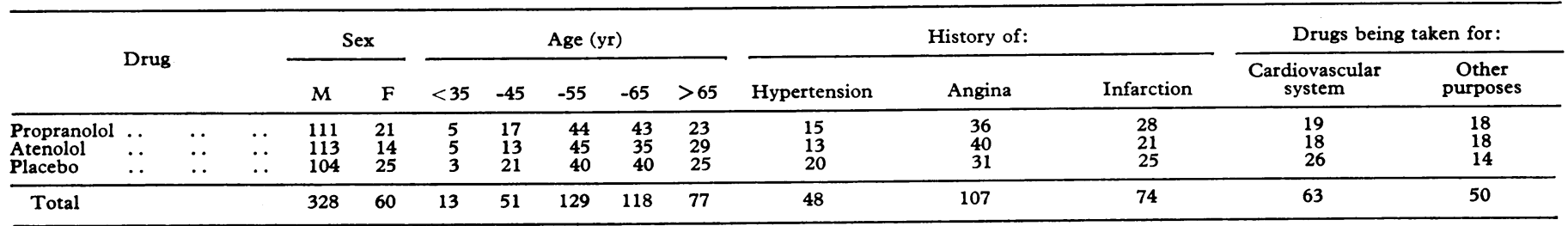


lol were withdrawn between the follow-up at six weeks and the end of the year of treatment, as were nine given atenolol and 10 given placebo. These withdrawals were due to non-specific symptoms, and there were no further withdrawals because of bradycardia or hypotension. Some withdrawn patients (seven from those given propranolol, 10 from those given atenolol, and 12 from those given placebo) were subsequently given beta-blockers during the year of follow-up, mainly for angina.

\section{EFFECT OF TREATMENT ON HEART RATE AND BLOOD PRESSURE}

Treatment with beta-blockers produced a reduction in pulse rate within 2 hours and in blood pressure within 24 hours. The initial mean pulse rates for the three groups were similar: propranolol 81 beats $/ \mathrm{min}$, atenolol 78 beats $/ \mathrm{min}$, and placebo 80 beats $/ \mathrm{min}$. For those patients who remained on trial tablets for at least 24 hours the mean minimum and mean maximum pulse rates were: propranolol 59 and 91 beats/min, atenolol 55 and 87 beats $/ \mathrm{min}$, and placebo 67 and 100 beats $/ \mathrm{min}$. These differences persisted while the patients remained on tablets, and at the six-week clinic the mean recorded heart rates were : propranolol 64 beats $/ \mathrm{min}$, atenolol 61 beats $/ \mathrm{min}$, and placebo 80 beats $/ \mathrm{min}$.

The initial mean blood pressures were similar: propranolol 149/ $92 \mathrm{~mm} \mathrm{Hg}$, atenolol $144 / 90 \mathrm{~mm} \mathrm{Hg}$, and placebo $147 / 92 \mathrm{~mm} \mathrm{Hg}$. After the first 24 hours the mean minimum and mean maximum blood pressures were: propranolol $106 / 67$ and $148 / 95 \mathrm{~mm} \mathrm{Hg}$, atenolol $106 / 67$ and $147 / 96 \mathrm{~mm} \mathrm{Hg}$, and placebo $112 / 72$ and $149 /$ $95 \mathrm{~mm} \mathrm{Hg}$. During the next 24 hours the mean maximum blood pressure in the groups given beta-blockers was reduced by a further $25 / 15 \mathrm{~mm} \mathrm{Hg}$ compared with $18 / 10 \mathrm{~mm} \mathrm{Hg}$ for the placebo group. At six weeks the mean blood pressure in those patients still on tablets was: propranolol 126/78 $\mathrm{mm} \mathrm{Hg}$, atenolol 125/76 $\mathrm{mm} \mathrm{Hg}$, and placebo $136 / 86 \mathrm{~mm} \mathrm{Hg}$ for patients diagnosed as having had a myocardial infarction, and $137 / 82 \mathrm{~mm} \mathrm{Hg}, 131 / 80 \mathrm{~mm} \mathrm{Hg}$, and $143 / 88 \mathrm{~mm} \mathrm{Hg}$ respectively for patients in other diagnostic categories.

\section{DEATHS}

Table $\mathrm{V}$ shows that by six weeks $10(7 \cdot 5 \%)$ of the patients initially treated with propranolol had died, as had $11(8.5 \%)$ of those initially treated with atenolol and $15(11.6 \%)$ of those given placebo. These differences were not significant $\left(\chi^{2}=1 \cdot 36,2\right.$ degrees of freedom).

TABLE V-Mortality at six weeks in patients treated until time of death and in those withdrawn from treatment

\begin{tabular}{|c|c|c|c|c|c|c|c|c|c|}
\hline \multirow[b]{3}{*}{$\begin{array}{l}\text { No of patients } \\
\text { Deaths } \ldots\end{array}$} & \multirow[b]{3}{*}{. } & \multirow[b]{3}{*}{$\begin{array}{l}\cdots \\
\cdots\end{array}$} & \multirow[b]{3}{*}{ 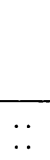 } & \multicolumn{6}{|c|}{ Drug } \\
\hline & & & & \multicolumn{2}{|c|}{$\begin{array}{l}\text { Propranolol } \\
(n=132)\end{array}$} & \multicolumn{2}{|c|}{$\begin{array}{l}\text { Atenolol } \\
(\mathrm{n}=127)\end{array}$} & \multicolumn{2}{|c|}{$\begin{array}{l}\text { Placebo } \\
(\mathrm{n}=129)\end{array}$} \\
\hline & & & & $\begin{array}{c}88 c \\
3\end{array}$ & $\begin{array}{c}44 w \\
7\end{array}$ & $\begin{array}{c}76 c \\
2\end{array}$ & $\begin{array}{c}51 w \\
9\end{array}$ & $\begin{array}{l}89 c \\
10\end{array}$ & $\begin{array}{c}40 w \\
5\end{array}$ \\
\hline \multicolumn{3}{|c|}{ Total No $\left({ }^{\prime}{ }_{0}^{\prime}\right)$ deaths } & & \multicolumn{2}{|c|}{$10(7 \cdot 5)$} & \multicolumn{2}{|c|}{$11(8 \cdot 6)$} & \multicolumn{2}{|c|}{$15(11 \cdot 6)$} \\
\hline
\end{tabular}

$c=$ Drug continued. $\mathbf{w}=$ Drug withdrawn.

Table $\mathrm{V}$ also shows that the mortality rate among the patients receiving placebo was similar whether they continued in the trial (10 out of 89) or were withdrawn from it ( 5 out of 40 ). In both groups treated with beta-blockers, however, there was a higher mortality rate in those who were withdrawn from treatment than in those who continued with it. Thus in the group treated with propranolol there were seven $(15.9 \%)$ deaths in 44 patients who were withdrawn from treatment compared with three $(3.4 \%)$ among those who continued with it. In the group of patients initially treated with atenolol nine $(17.6 \%)$ of the 51 patients withdrawn from treatment died, compared with two $(2 \cdot 6 \%)$ of the 76 who continued with it. For the withdrawn patients who subsequently died there was no significant difference between the three groups in the number of days on tablets before withdrawal (three days for those taking propranolol, two for those taking atenolol, and three for those taking placebo) or the interval between withdrawal and the day of death (seven days, 17 days, and seven days respectively), suggesting that withdrawal of the beta-blockers was not harmful.

At six weeks patients initially admitted to the trial with suspected infarction who had not developed confirmatory evidence of infarction and who had no past history of ischaemic heart disease were removed from the study but continued to attend follow-up examinations. Those with another diagnosis had already been withdrawn. The numbers of patients in the trial after six weeks, therefore, were 98 in the group initially given propranolol, 92 in the group initially given atenolol, and 83 in the group initially given placebo. Table VI shows that each of these groups contained patients who had already been withdrawn from treatment during the first six weeks. Since we wished

TABLE VI-Patient outcome from six weeks to one year after start of trial

\begin{tabular}{|c|c|c|c|c|c|c|}
\hline \multirow{3}{*}{ Outcome } & \multicolumn{6}{|c|}{ Drug } \\
\hline & \multicolumn{2}{|c|}{ Propranolol } & \multicolumn{2}{|c|}{ Atenolol } & \multicolumn{2}{|c|}{ Placebo } \\
\hline & c & $\mathbf{w}$ & c & $\mathrm{w}$ & c & $\mathbf{w}$ \\
\hline $\begin{array}{l}\text { No alive at } 6 \text { weeks } \\
\text { No remaining at } 6 \text { weeks after }\end{array}$ & 85 & 37 & 74 & 42 & 79 & 35 \\
\hline $\begin{array}{l}\text { protocol withdrawal } \ldots \\
\text { No at } 1 \text { year } \\
\text { Deaths from } 6 \text { weeks to }\end{array}$ & $\begin{array}{l}69 \\
52\end{array}$ & $\begin{array}{l}29 \\
17+29\end{array}$ & $\begin{array}{l}56 \\
47\end{array}$ & $\stackrel{36}{9}+36$ & $\begin{array}{l}59 \\
49\end{array}$ & $\begin{array}{l}24 \\
10+24\end{array}$ \\
\hline 1 year... ... & 2 & $1+4$ & 2 & $2+4$ & 0 & $1+3$ \\
\hline Total deaths at 1 year & 5 & 12 & 4 & 15 & 10 & 9 \\
\hline
\end{tabular}

$c=$ Drug continued. $w=$ Drug withdrawn

to analyse our results according to the initial intention-to-treat allocation as well as by the medication currently being taken between each follow-up examination, all those withdrawn from treatment were followed up in the same way as those who remained on it. Table VI shows the outcome in each treatment group between six weeks and one year and the total mortality at one year according to whether the patient was continuing with treatment or had been withdrawn from it. None of the differences in mortality were significant.

Of the 55 deaths that occurred during the study, 49 were ascribed to cardiovascular causes. The other causes of death were as follows : in the propranolol group one patient died from chronic renal failure and one from bronchopneumonia; in the atenolol group one patien died in a road traffic accident and two from pancreatic carcinoma; and one patient in the placebo group died from bronchial carcinoma The deaths due to cardiovascular causes during the initial stay in hospital consisted of those due to cardiogenic shock, cardiac rupture, reinfarction, or pulmonary embolism. The deaths after discharge from hospital occurred mainly before the arrival of medical help.

\section{RECORDED SYMPTOMS}

Recorded symptoms were commoner in the patients taking propranolol and atenolol than in patients given placebo. In particular $30 \%$ of patients taking beta-blockers either claimed spontaneously or admitted on questioning to having cold hands and feet compared with $7 \%$ of patients taking placebo $(p<0 \cdot 001)$. Muscle fatigue occurred in $22 \%$ of patients taking beta-blockers and in $13 \%$ of those taking placebo $(\mathrm{p}<0.05)$. "Bowel upsets" were recorded in $19 \%$ of patients taking beta-blockers and in $4 \%$ of patients taking placebo $(\mathrm{p}<0.001)$. On the other hand, angina was reported in $10 \%$ of patients taking beta-blockers and in $19 \%$ of patients taking placebo $(\mathrm{p}<0.05)$

\section{Discussion}

Most deaths from myocardial infarction occur soon after the onset of symptoms, ${ }^{8}$ so that it is important to begin any potentially useful treatment as soon as possible; in hospital practice this will usually mean when the patient is admitted to a coronary care unit. Studies of the effectiveness of immediate treatment have, however, disadvantages that seem inescapable. The decision whether to include a patient in such a study must be made on the basis of the history and first electrocardiogram, since the results of serial enzyme estimations and electrocardiograms are not available. An early-entry study must, therefore, be performed in patients with suspected rather than confirmed myocardial infarction, and inevitably some of the patients treated will ultimately prove not to have had an infarction. 
Thus it is important to follow up all the patients entering the study since the treatment under scrutiny might be harmful rather than beneficial to patients who were initially suspected of having myocardial infarction but in whom another condition was later diagnosed. An early-entry study must, therefore, be analysed on the basis of the initial intention to treat and on the initial criteria used to enter patients. All patients, irrespective of subsequent changes in diagnosis or withdrawal from the trial, must be followed up and overall benefit or harm assessed in each original intention-to-treat category.

Patients in the early stages of infarction are likely to develop complications such as changes of heart rate, rhythm, and output. If the treatment under investigation is believed by the participating doctors to potentiate such complications then a high withdrawal rate is inevitable. Since beta-blockers reduce heart rate and blood pressure, patients included in a trial of beta-blockade are likely to be withdrawn if they develop bradycardia or hypotension. Thus, if a patient who is receiving placebo develops a fall in blood pressure or pulse rate due to infarction the supervising doctor may attribute this to betablockade and wish to withdraw the patient because he fears that he is causing harm. Alternatively, a patient in the trial might develof dysrhythmias that the supervising doctor would normally treat with beta-blockers. The doctor might then wish to withdraw the patient because he fears that he is receiving placebo and is being harmed by not receiving beta-blockers. Thus doctors' beliefs and their fears of harm by commission (giving beta-blockers) or omission (not giving beta-blockers) will influence the withdrawal rate. Since beta-blockers do actually lower blood pressure and pulse rate there will be a higher withdrawal rate in the treated patients because the withdrawals due to the effects of the drug will add to the withdrawals due to the doctors' beliefs.

The high withdrawal rate in the placebo group in our study shows that the doctors believed that the tablets were harming their patients by commission or omission. This problem would be less important in a late-entry study, and after two or three days the results of enzyme analyses and serial electrocardiograms would be available so that only patients with clear evidence of infarction would need to be included. Unfortunately, by then most of the deaths would have already occurred so the chances of affecting mortality would be reduced. Although compounds such as beta-blockers are thus more readily tested in late-entry studies, their chances of influencing outcome may then be minimal.

Studies of beta-blockers in acute myocardial infarction have been criticised because of inadequate dosage. The doses we used greatly reduced heart rate and blood pressure, causing a high withdrawal rate despite our liberal criteria for hypotension and bradycardia. Hence, higher doses could not have been used unless we had relaxed our criteria. The higher withdrawal rate in the atenolol-treated patients shows that atenolol in the dosage used lowered blood pressure and pulse rate more effectively than propranolol, although we used doses that are considered to be equipotent in reducing these indices. ${ }^{9}$ Thus the circulatory changes accompanying myocardial infarction probably alter the absorption, distribution, or excretion of these drugs.

A possible conclusion from our results is that beta-blockers were beneficial because the death rate in the patients continuing on the agents was lower than that in patients continuing on placebo (deaths up to six weeks: three in the propranolol group, two in the atenolol group, and 10 in the placebo group; and up to one year: five, four, and 10 respectively). The high withdrawal rate, however, makes interpretation of our results difficult. There were more deaths among patients who were withdrawn from treatment with propranolol or atenolol than in those who continued with treatment. There was no evidence that treatment was harmful, since patients withdrawn from the groups treated with beta-blockers did not die sooner after withdrawal than those who died after withdrawal from placebo. Moreover, the overall death rate in the first two groups was not increased.
Beta-blockade may have harmed some patients and helped others: the recent alprenolol study ${ }^{5}$ has shown a differential effect in patients aged under and over 65 . We therefore analysed our results according to age and sex distribution but could find no evidence of this. The response to beta-blockers appears to identify a high-risk group of patients who were more likely to develop bradycardia and hypotension when treated with the active drugs and were, therefore, more likely to be withdrawn from treatment. The similar mortality among the groups of patients continued on placebo or withdrawn from it supports this concept.

The only satisfactory way to analyse the results of any intervention study such as ours is according to intention to treat. All patients initially allocated to any treatment group must be considered together whether or not they are withdrawn from treatment. The doctor whose patient has a suspected myocardial infarction needs to know whether or not immediate prophylactic treatment with a beta-blocker is likely to be helpful: the results of our study suggest that it is not, because the one-year survival rates did not differ significantly in the three treatment groups. It might be argued that our study has failed to detect a small effect on mortality. A large, multicentre trial, with its attendant problems of ensuring comparability of entry and management between centres, would be needed to exclude such a type II statistical error, and in our view practising doctors will conclude that if benefit to patients cannot be shown by a trial such as ours then it cannot be large enough to make a valuable contribution to the management of their patients with suspected myocardial infarction.

This study was made possible by a generous grant from Imperial Chemical Industries Limited. We thank Professor A F M Smith and $\operatorname{Dr}$ A M Skene, department of mathematics, University of Nottingham, for undertaking the detailed statistical analysis; Professor P H Fenton, department of physiology, Medical School, University of Nottingham; Mrs Jackie Walls, pharmacist, General Hospital, Nottingham; and all the consultant physicians and junior medical and coronary-care-unit staff at the City and General Hospitals, Nottingham, for their help during this trial.

\section{References}

1 Snow PJD. Effect of propranolol in myocardial infarction. Lancet 1965; ii :551-3.

${ }^{2}$ Balcon R, Jewitt DE, Davies JPH, Oram S. A controlled trial of propranolol in acute myocardial infarction. Lancet 1966;ii:917-20.

${ }^{3}$ Clausen J, Felsby $M$, Jørgensen FS, Nielsen BL, Roin J, Strange B. Absence of prophylactic effect of propranolol in myocardial infarction. Lancet 1966;ii:920-4.

4 Bath JCJL, Blake S, Bloom RA, et al. Propranolol in acute myocardial infarction. Lancet 1966 ;ii:1435-8.

5 Andersen MP, Bechsgaard P, Frederiksen J, et al. Effect of alprenolol on mortality among patients with definite or suspected acute myocardial infarction. Lancet 1979 ;ii:865-7.

6 Rutherford JD, Singh BN, Ambler PK, Norris RM. Plasma propranolol concentration in patients with angina and acute myocardial infarction. Clin Exp Pharmacol Physiol 1975;3:297-305.

7 Roland JM, Wilcox, RG, Banks DC, Edwards B, Fentem PH, Hampton JR. Effect of beta-blockers on arrhythmias during six weeks after suspected myocardial infarction. Br Med 7 1979;ii:518-21.

${ }^{8}$ Fulton M, Julian DG, Oliver MF. Sudden death and myocardial infarction. Circulation 1969;39-40, suppl IV:182-91.

${ }^{9}$ Hansson L, Westerlund A, Aberg H, Karlberg BE. A comparison of the antihypertensive effect of atenolol (ICI 66082) and propranolol. Eur f Clin Pharmacol 1976;9:361-5.

(Accepted 28 fanuary 1980)

ONE HUNDRED YEARS AGO We are glad to learn that the Medway Union Guardians have resolved that the children in the union schools shall be taught swimming by competent persons at their new baths, about to be opened. The guardians were unanimously of opinion that the art of swimming should be part of the education of the children of both sexes. (British Medical fournal, 1880.) 